\title{
Conversion of Potato Peel Waste to Single Cell Protein by an Acidophilic Fungus
}

\author{
Sanna Taskila1, Mikko Ahokas', Ville-Hermanni Sotaniemi', Marianne Mäki ${ }^{2,3}$, \\ Hanna-Liisa Malinenn',3, Mari Jaakkola ${ }^{2,3}$, Hanna Virpiranta', Juha Tanskanen' \\ ${ }^{1}$ Chemical Process Engineering Research Unit, University of Oulu, Oulu, Finland \\ ${ }^{2}$ Unit of Measurement Technology, University of Oulu, Oulu, Finland \\ ${ }^{3}$ Kajaani University Consortium, Kajaani, Finland \\ Email: sanna.taskila@oulu.fi
}

How to cite this paper: Taskila, $S$., Ahokas, M., Sotaniemi, V.-H., Mäki, M., Malinen, H.-L., Jaakkola, M., Virpiranta, H. and Tanskanen, J. (2018) Conversion of Potato Peel Waste to Single Cell Protein by an Acidophilic Fungus. Journal of Water Resource and Protection, 10, 522-532. https://doi.org/10.4236/jwarp.2018.105028

Received: April 10, 2018

Accepted: May 27, 2018

Published: May 30, 2018

Copyright $\odot 2018$ by authors and Scientific Research Publishing Inc. This work is licensed under the Creative Commons Attribution International License (CC BY 4.0).

http://creativecommons.org/licenses/by/4.0/

\begin{abstract}
The aim of this research was to convert potato peel waste (PPW) to single cell protein (SCP), and to extract valuable phenolic compounds from the spent medium. PPW is an abundant by-product of potato processing industry, consisting mostly of starch, fibre and protein in a form of watery sludge. The PPW from a chip manufacturing plant was pre-treated with sulphuric acid, and used as a substrate for an acidophilic Scytalidium acidophilum fungus under non-aseptic conditions. The produced SCP had a promising amino acid composition to be used in animal feed. Phenolic compounds were not recovered from the spent medium, most likely due to the low $\mathrm{pH}$ in the medium. The present findings suggest that PPW is a suitable raw material for acidophilic SCP production, whilst the extraction of phenolic acids would require milder cultivation conditions or separation before pre-treatments of SCP production. The BOD5 of the PPW was reduced by in $98 \%$ due to fungal cultivation. Thus the feed production also served as an efficient means for reduction of organic load in the PPW.
\end{abstract}

\section{Keywords}

Potato Peel Waste, PPW, Single Cell Protein, SCP, Scytalidium acidophilum, Acidophilic, Phenolic Acid, Non-Aseptic

\section{Introduction}

Potato (Solanum tuberosum) is widely used staple food and different potato products are manufactured in industrial level all over the world. Washing and subsequent peeling are the first steps in the industrial processing of potato. Po- 
tato processing industries produce peel sludge (PPW, potato peel waste), which accounts to $38 \%$ - $53 \%$ of the total potato material, depending on season and employed peeling process [1]. The solid content of PPW is low, namely $2 \%$ $25 \%$, which is partly due to water absorbed by potato fiber [2] [3] and starch granules [4]. The solid phase of PPW contains 30\% - 85\% starch, $24 \%-65 \%$ fiber and $6.2 \%$ - $18.6 \%$ protein [3] [5] [6], depending on seasonal variability of potato and occupied peeling technique.

Typically PPW is directed for animal feed producers or biogas plants to avoid sludge processing cost. Despite disadvantages related to high potassium and phosphorus concentration in potato peels, and the effect of seasonal production to the availability, use as feed is still regarded as the most feasible alternative for the sludge treatment. The alternative applications for PPW, such as production of ethanol and other biochemicals [7] [8] or biobased materials [5], have not yet been absorbed by potato industry.

The microbial upgrading to protein-rich feed, i.e. single cell protein (SCP) is one proposed option for the valorization of PPW [9] [10] [11]. The advantages of SCP production as compared to other proposed applications include the possibility to utilize existing value chains for animal feed, and to increase the solid content and nutritional value of feed. Already over 40 years ago, Tomlinson investigated the feasibility of SCP production from food industry wastes, including potato residues by several strains of filamentous fungi and yeasts [10] [11]. Feasibility analysis suggested that the conversion of potato residues to SCP would offer a cost-efficient solution for the costly wastewater treatment processes, especially when operation under non-aseptic conditions is possible. Acidophilic conversion of potato waste to SCP was investigated by Stevens and Gregory with fungus Cephalosporium eichhorniae 152 [12]. The used pH of 3.75 did not allow non-aseptic conditions.

The present research aimed at the conversion of PPW to SCP under low pH without the requirement for asepticity. The selected fungus, Scytalidium acidophilum, was originally isolated in the proximity of uranium mine drainage and sulphur stockpiles [13] [14]. It holds extraordinary features, such as ability to grow at $\mathrm{pH} 0$ and in the presence of $4 \%$ of copper sulphate [15]. The previously reported applications of $S$. acidophilum indicated its potential for the bioconversion of acidic wastes or waste hydrolysates into single cell protein [13] [16] [17] [18] [19]. In addition, fungi provide, to some extent a favorable composition especially in terms of relatively low nucleic acid concentration [20].

Due to the extensive industrial production volume and low raw material price, potato peels are also an interesting source of bioactive phenolic compounds. According to a recent overview, almost $50 \%$ of phenolic compounds are located in the peel and adjoining tissues of potato and most abundant of those compounds are phenolic acids, especially chlorogenic acids [21]. Therefore, to assess the alternative for combined single cell protein production and phenolic compounds extraction from PPW, the chlorogenic acid concentrations were measured after fungal cultivations and in different types of PPW materials. 


\section{Material and Methods}

\subsection{Potato Peel Waste}

PPW of white-flesh potatoes from a hot steam peeling process was provided by a local potato products manufacturing plant. Additionally for phenolic acids measurements raw abrasive peeled PPW was provided by a local vegetable peeling enterprise and laboratory scale potato peel samples were obtained by traditional hand peeling of potatoes from local supermarket. All samples were stored at $-20^{\circ} \mathrm{C}$ upon experiments.

The 5-day biological oxygen demand (BOD5) values were measured with manometric respirometric test using OxiTop Control system (WTW, Weilheim, Germany). This method is based on an automatic pressure measurement in a closed bottle at a temperature of $20^{\circ} \mathrm{C}$. Oxygen is consumed by micro-organisms during the biodegradation of the organic carbon. The formed $\mathrm{CO}_{2}$ is absorbed to $\mathrm{NaOH}$ pellets and the resulted pressure drop is measured by a pressure sensor and used as a measure of the BOD $\left(\mathrm{mg} \cdot \mathrm{L}^{-1}\right)$.

The used BOD measuring range was $0-4000 \mathrm{mg} \cdot \mathrm{L}^{-1}$ and corresponding sample volume $22.7 \mathrm{~mL}$ (WTW, Weilheim, Germany). The PPW samples were diluted with nutrient solution containing $10 \mathrm{~mL}$ of phosphate buffer $(\mathrm{pH} 7.2)$ and $1 \mathrm{~mL}$ of mineral solutions (22.5 $\mathrm{g} \mathrm{MgSO}_{4} \cdot 7 \mathrm{H}_{2} \mathrm{O} \mathrm{L}^{-1}, 27.5 \mathrm{~g} \mathrm{CaCl}_{2} \mathrm{~L}^{-1}, 0.25 \mathrm{~g}$ $\mathrm{FeCl}_{3} \cdot 6 \mathrm{H}_{2} \mathrm{O} \mathrm{L}^{-1}$ ) per litre. The used dilution factor was 30 . All the measurements were carried out duplicate with and without the inoculum addition. The inoculum used was collected from a domestic wastewater plant, Oulu Waterworks. The volume of the filtered seed used was $5 \mathrm{~mL}$ per litre of undiluted sample. The addition of seed did not seem to have an influence on the BOD results.

The chemical oxygen demand (COD) values were measured using Hach Lange COD cuvette tests LCK 014 (measuring range 1 - $10 \mathrm{~g} \cdot \mathrm{L}^{-1}$ ) or LCK 914 (measuring range 5 - $60 \mathrm{~g} \cdot \mathrm{L}^{-1}$ ). Test cuvettes contain all needed reagents: sulphuric acid, potassium dichromate, silver sulphate and mercury sulphate. Sample digestions were carried out with Hach Lange HT $200 \mathrm{~S}$ and spectrophotometric analyses with UV/Vis Spectrophotometer Hach Lange DR 2800. The BOD and COD of the original (industrial) PPW were 70,000 $\pm 10,000$ and 120,000 \pm $2000 \mathrm{mg} \cdot \mathrm{L}^{-1}$.

\subsection{Fungal Strain}

S. acidophilum strain 26,774 was acquired from ATCC-LGC Standards Partnership (U.S). Pre-cultures of $S$. acidophilum were grown in Potato Dextrose Agar (PDA) including $300 \mathrm{~g} \cdot \mathrm{L}^{-1}$ diced potatoes, $20 \mathrm{~g} \cdot \mathrm{L}^{-1}$ glucose and $15 \mathrm{~g} \cdot \mathrm{L}^{-1}$ agar in distilled water.

\subsection{Hydrolysis and Cultivations}

A $64 \mathrm{~g}$ portion of peel waste was hydrolyzed first with $64 \mathrm{~mL}$ of $72 \% \mathrm{H}_{2} \mathrm{SO}_{4}$ at $+4^{\circ} \mathrm{C}$ overnight, followed by addition of $1500 \mathrm{~mL}$ of medium $\left(0.5-1.5 \mathrm{~g} \mathrm{~L}^{-1}\right.$ 
yeast extract, 2.5 - $7.5 \mathrm{~g} \cdot \mathrm{L}^{-1}$ potassium di-hydrogen phosphate $\left.\left(\mathrm{KH}_{2} \mathrm{PO}_{4}\right)\right)$ and further incubation at $98^{\circ} \mathrm{C}$ for $1 \mathrm{~h}$. The $\mathrm{pH}$ of hydrolysate was adjusted to 1.5 with $70 \mathrm{~mL}$ of $10 \mathrm{M} \mathrm{NaOH}$ before inoculation. The inocula for growth experiments were prepared from PDA plates by suspension of cells into $2 \mathrm{~mL}$ of sterile $0.9 \%$ saline, and transfer to the bioreactor. Fermentation temperature was $30^{\circ} \mathrm{C}$. The fermenters were $3 \mathrm{~L}$ glass bioreactors equipped with Rushton impeller and aeration sparger. The total liquid volume was approximately $1600 \mathrm{~mL}$ in each bioreactor run. The cultures were aerated maintaining the dissolved oxygen tension above $20 \%$ during the whole cultivation. The final cell mass was harvested with filtration and stored at $-20^{\circ} \mathrm{C}$ upon further analyses. The effect of mixing on biomass yield was investigated by fermentations with and without mixing using Rushton impeller at 0 or $400 \mathrm{rpm}$. Cultures were harvested after $72 \mathrm{~h}$ of fermentation by vacuum filtration onto filter paper.

\subsection{Determination of Dry Weight}

Dry weight (DW) was determined for biomass filtrates at the end of the cultivation. The measurements were prepared by filtration of cultures through pre-weighted what man paper followed by incubation at $60^{\circ} \mathrm{C}$ until constant weight. The dry weight of peel waste, measured after drying triplicate samples at $60^{\circ} \mathrm{C}$ for 2 days, was $0.152 \pm 0.06 \mathrm{~g} \cdot \mathrm{g}^{-1}$.

\subsection{Analysis of Proteins and Amino Acids}

Total protein content was analyzed by Kjeldahl method according to AACC 46 12. Prior to amino acid analyses samples were hydrolysed in $6 \mathrm{M} \mathrm{HCl}(20 \mathrm{~h}$, $110^{\circ} \mathrm{C}$ ) according to method of [22]. Amino acid analysis was performed by high-performance liquid chromatography (Agilent 1100 Series HPLC, Agilent Technology) instrument using commercial kit AccQ Tag Chemistry Package (WAT052875, Waters), that contained AccQ Tag column (60 A, $4 \mu \mathrm{m}, 3.9 \times 150$ $\mathrm{mm}$, Waters), eluent solvents and 19 amino acid standards. In addition, a Nova-Pak C18 guard column ( $60 \AA$, $4 \mu \mathrm{m}, 3.9 \times 20 \mathrm{~mm}$, Waters) was used. Detection was performed with fluorescence using wavelengths of $250 \mathrm{~nm}$ for excitation and $395 \mathrm{~nm}$ for emission.

\subsection{Analysis of Phenolic Acids}

Phenolic acids were analyzed by high-performance liquid chromatography (Agilent 1100 Series HPLC, Agilent Technology) connected to a diode array detector (DAD). Analyses were performed on a Hyper Clone ODS (C18) column (120 ̊, $5 \mu \mathrm{m}, 2.0 \times 200 \mathrm{~mm}$, Phenomenex). Phenolic acids were quantified at $260 \mathrm{~nm}$, or $320 \mathrm{~nm}$, depending on their absorbance maximum. The used HPLC method was described in details in earlier publications [23] [24]. The authentic chemical compounds used for identification and quantification of phenolic acids were protocatechuic, benzoic, vanillic, syringic, sinapic, trans-cinnamic, p-coumaric, caffeic, p-hydroxybenzoic, gallic, ferulic and chlorogenic acid. 


\subsection{Design of Experiments and Response Surface Modeling}

Response surface methodology (RSM) using MODDE software for Design of Experiments and Optimization (Version 8.0.0.0, UMETRICS AB, Umeå, Sweden) was employed to investigate the effects of growth conditions on protein and amino acid yields. The RSM was prepared using quadratic face centered central composite design (CCF). The performances of the models were evaluated by assessing analysis of variance (ANOVA) as described in [25]. Briefly, with good models, the standard deviation of the model should be much larger than the standard deviation of the noise with its upper confidence level. The effect of a factor can be considered statistically significant if the confidence interval is not larger than the effect itself. Factors under investigation were mixing (with or without), hydrolysis with sulphuric acid (with or without) and medium supplements (low and high level). The experiment matrix is presented in Table 1.

\section{Results and Discussion}

\subsection{Growth of S. acidophilum on PPW}

The quantities of protein and amino acids before and after fungal cultivations were calculated from three repetitive hydrolysis and fermentation experiments (400 rpm mixing and $0.5 \mathrm{vvm}$ aeration). The average quantities of protein and amino acids before cultivations were 0.83 and $0.55 \mathrm{~g}$, and after cultivations 1.96 \pm 0.30 and $1.54 \pm 0.17 \mathrm{~g}$. Accordingly, over 2 -fold increase in the protein and amino acid quantities were achieved by the cultivation (Table 2). Glutamate was the most abundant amino acid in the original PPW, and thus also in the final biomasses. The amino acid composition of produced biomass was similar to that of Aspergillus niger [20], which indicates good compatibility in animal feed (Table 3). Further work will however be necessary to assess the quality aspects of the product.

\subsection{Effect of Hydrolysis, Mixing and Supplementation on SCP}

The effects of hydrolysis, mixing and supplement concentrations on yields of

Table 1. Experiment matrix for RSM.

\begin{tabular}{ccccc}
\hline \multirow{2}{*}{$\begin{array}{c}\text { Experiment } \\
\text { number }\end{array}$} & \multicolumn{4}{c}{ Conditions } \\
\cline { 2 - 5 } & Mixing $(\mathrm{rpm})$ & Hydrolysis & Yeast extract $\left(\mathrm{g} \cdot \mathrm{L}^{-1}\right)$ & $\mathrm{K}_{2} \mathrm{HPO}_{4}\left(\mathrm{~g} \cdot \mathrm{L}^{-1}\right)$ \\
\hline 1 & 0 & yes & 0.5 & 2.5 \\
2 & 400 & yes & 1 & 5 \\
3 & 400 & yes & 1 & 5 \\
4 & 400 & yes & 1 & 5 \\
5 & 400 & no & 0.5 & 2.5 \\
6 & 0 & no & 1.5 & 7.5 \\
7 & 0 & no & 1.5 & 7.5 \\
\hline
\end{tabular}


Table 2. The properties of filtrate and supernatant after each bioreactor run.

\begin{tabular}{cccc}
\hline \multirow{2}{*}{ Experiment number } & \multicolumn{3}{c}{ Yield from PPW $\left(\mathrm{g} \cdot \mathrm{g}^{-1}\right)$} \\
\cline { 2 - 4 } & Protein & Amino acids & Wet biomass filtrate \\
\hline 1 & 0.008 & 0.006 & 0.133 \\
3 & 0.032 & 0.023 & 0.464 \\
4 & 0.025 & 0.022 & 0.323 \\
5 & 0.035 & 0.027 & 0.602 \\
6 & 0.061 & 0.007 & 0.564 \\
7 & 0.021 & 0.010 & 0.595 \\
& 0.006 & 0.006 & 0.119 \\
\hline
\end{tabular}

Table 3. Amino acid compositions of original PPW and biomass after hydrolysis and cultivation.

\begin{tabular}{|c|c|c|}
\hline \multirow{2}{*}{ Amino acid } & \multicolumn{2}{|c|}{ Proportion (\%) from total amino acids } \\
\hline & Original PPW & PPW and fungal biomass \\
\hline Glutamate & 15.9 & $13.54 \pm 0.77$ \\
\hline Aspartate & 18.30 & $9.85 \pm 0.63$ \\
\hline Leucine & 6.85 & $7.93 \pm 0.40$ \\
\hline Lysine & 6.54 & $7.40 \pm 0.72$ \\
\hline Phenylalanine & 7.98 & $6.64 \pm 2.12$ \\
\hline Arginine & 3.92 & $6.87 \pm 0.67$ \\
\hline Alanine & 5.54 & $6.00 \pm 0.20$ \\
\hline Valine & 5.42 & $5.94 \pm 0.13$ \\
\hline Serine & 4.72 & $5.79 \pm 0.16$ \\
\hline Threonine & 4.35 & $5.56 \pm 0.25$ \\
\hline Glycine & 4.23 & $5.56 \pm 0.12$ \\
\hline Isoleucine & 3.83 & $4.70 \pm 0.15$ \\
\hline Proline & 3.84 & $4.44 \pm 0.19$ \\
\hline Tyrosine & 3.18 & $3.57 \pm 0.47$ \\
\hline Histidine & 1.89 & $2.84 \pm 0.09$ \\
\hline Methionine & 2.18 & $2.34 \pm 0.05$ \\
\hline Cystein & 1.10 & $1.02 \pm 0.49$ \\
\hline
\end{tabular}

protein and individual amino acids were investigated by means of RSM. The hydrolysis of PPW with sulphuric acid and heating before fermentation did not affect the final yield of proteins (Table 4). However, the yield of intact amino acids in the protein fraction was higher when the samples were hydrolyzed, indicating that the hydrolysis is advantageous for the quality of feed product. Most likely this result is due to intact potato proteins being present in the non-hydrolyzed samples and thus showing in the final protein yield, but not anymore in the hydrolyzed (heated) ones. 
Table 4. Scaled effects of the investigated factors on responses protein yield, amino acid yield and net weight of the biomass filtrate with confidence intervals ( $95 \%$ confidence).

\begin{tabular}{cccc}
\hline \multirow{2}{*}{ Factor } & \multicolumn{3}{c}{ Response } \\
\cline { 2 - 4 } & Protein yield & Amino acid yield & Net weight of wet filtrate \\
\hline Supplement & $-4.15 \pm 2.77$ & $0.24 \pm 0.24$ & $-0.55 \pm 45.67$ \\
Mixing & $2.99 \pm 2.43$ & $-0.10 \pm 0.21$ & $8.84 \pm 40.06$ \\
Hydrolysis & $-1.87 \pm 2.77$ & $0.52 \pm 0.21$ & $-18.75 \pm 40.06$ \\
\hline
\end{tabular}

Mixing increased SCP yield, supposedly due to improved oxygen supply for the culture which promoted the growth of fungus. Similar effect of improved oxygen supply on the growth of $S$. acidophilum was described earlier in [13]. Also, the medium with $1 \mathrm{~g} \cdot \mathrm{L}^{-1}$ yeast extract and $5 \mathrm{~g} \cdot \mathrm{L}^{-1} \mathrm{~K}_{2} \mathrm{HPO}_{4}$ proposed by [13] was found as suitable supplement for the cultivation of $S$. acidophilum in PPW. As could be expected, the further increase of supplement concentrations did not promote the growth of fungus in PPW [13]. Effects of supplement concentrations on the final amino acid concentrations were statistically insignificant. The net wet weight of the biomass, including original waste and fungal biomass, was independent of the investigated factors.

\subsection{On the Techno-Economic Aspects of the Process}

Based on the present research the process would compose of pre-treatment, including a $\mathrm{pH}$ adjustment and hydrolysis with sulphuric acid (Figure 1). This would be followed by non-aseptic cultivation of $S$. adicophilum under aeration for $72 \mathrm{~h}$. The produced biomass is dehydrated with solid-liquid separation and drying. Based on the present and previously published research, efficient aeration is a prerequisite of the SCP production by $S$. acidophilum [13] [16]. As has been suggested, the most economical choice for the plant would be similar as in the active sludge process [11]. In case of $S$. acidophilum the final biomass concentration would be relatively low, namely in the range of 5\% - 9\% dry matter [13] [16], while the final product should contain $10 \%$ or less moisture. This means that the harvesting and dehydrating are significant contributors to the production cost. The solid liquid separation for filamentous fungi is usually most feasibly prepared with filtration, after which the biomass is dried to maintain its quality [26].

Regarding the assessment of the process economy, the most straightforward way is to compare the cost of SCP production to the cost of the traditional wastewater treatment which is the most likely alternative for the processing of PPW [11]. Therefore, the BOD5 and COD values were measured from spent media of Experiment 3. The values were 423 and $2930 \mathrm{mg} \cdot \mathrm{L}^{-1}$, respectively, accounting for the reduction of $85 \%$ and $39 \%$ from the original PPW. This BOD reduction compares well to the previously presented reports [11], whereas the COD reduction can be considered more modest [27] [28]. However, the process optimization regarding the supplementation of nutrients may promote higher 


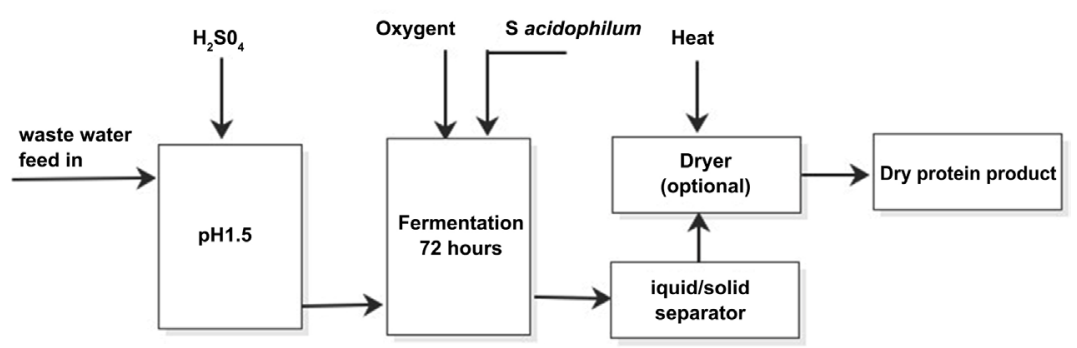

Figure 1. Proposed process flow sheet for the SCP production process.

COD reduction. Overall, the acidophilic SCP production seems promising alternative for other more costly wastewater treatment options.

\subsection{Phenolic Compounds before and after Fungal Cultivations}

Phenolic acid content in the PPW from a hot steam peeling process varied between 17 - $33 \mathrm{mg} 100 \mathrm{~g}^{-1}$ (fw) depending on sampling date in the factory $(\mathrm{n}=5)$ (Figure 2). The most abundant acid was, as expected, chlorogenic acid, which consisted $89 \%$ - $92 \%$ of all measured phenolic acids in the PPW. The residual acids consisted mainly of caffeic acid, in addition to which also p-hydroxybenzoic, protocatechuic and vanillic acids were detected. These results are in accordance with earlier findings where chlorogenic acid concentration in potato was re-

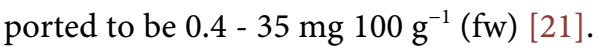

As a comparison to hot steam peeled PPW, phenolic acids were analyzed also in an industrial abrasive peeled PPW. Surprisingly, the concentrations of the

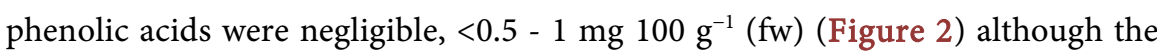
expectation was that raw abrasive peeling would be beneficial as samples were not exposed to high temperatures during processing. Effect of peeling method on the chlorogenic acid content was further studied by samples from raw potatoes, which were either 1) directly raw peeled by hand or 2) steam cooked for different durations (14 min or $28 \mathrm{~min}$ ) beforehand peeling. Chlorogenic acid concentration was only $1 \mathrm{mg} 100 \mathrm{~g}^{-1}$ in the raw hand peeled sample, whereas in the sample from the potato exposed for short duration $(14 \mathrm{~min})$ to hot steam the concentration was the highest, $26 \mathrm{mg} 100 \mathrm{~g}^{-1}$ (Figure 2). Longer cooking time (28 min) in the hot steam decreased the chlorogenic acid content significantly, although the concentration $\left(10 \mathrm{mg} 100 \mathrm{~g}^{-1}\right.$, fw) was still ten-fold higher than in both raw hand peeled and abrasive peeled potato PPW. Similar decrease of chlorogenic acid content was reported in publication where only $35 \%$ of the original chlorogenic acid was detected after $30 \mathrm{~min}$ boiling [29].

These results suggest that decreased concentration of chlorogenic acid in the raw peeled PPW may be caused e.g. by enzymatic degradation processes which seems to be activated during raw peeling methods, whereas short exposure to hot steam eliminates that activity. Extended hot steam exposure to high temperatures obviously also causes degradation of chlorogenic acid. Shorter exposure to the hot steam in laboratory experiments successfully mimic the industrial hot steam peeling process where potato is not fully cooked and hence chlorogenic 


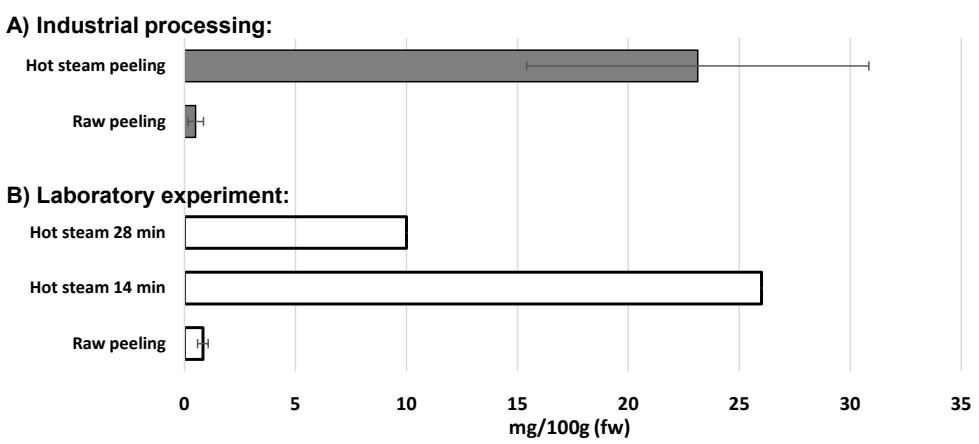

Figure 2. Effect of peeling technique on the content of chlorogenic acid in potato peel samples. A) Industrial processing samples were collected in five different days. B) Laboratory experiments were performed using raw potatoes, which were either directly raw peeled by hand, or steam cooked for different durations (14 $\mathrm{min}$ or $28 \mathrm{~min}$ ) beforehand peeling.

acid content remains more stable than in raw peeled or long time cooked PPW. To our best knowledge this is a new finding that has not been reported earlier.

Phenolic acids were not detected from the hydrolyzed and cultivated fermentation samples. Most probably, the processing in strong sulphuric acid solution was too harsh condition for phenolic acids. Thus, phenolic acids should be extracted from the sample before hydrolysis, or from side streams of other potato peel utilization processes. In addition, the peeling technique as well as other processing conditions needs to be carefully considered when the aim is to recover phenolic acids from PPW.

Content of phenolic compounds in PPW is not only depended on cultivar and potato storage conditions [21], but also peeling technique and PPW storage conditions after peeling affect significantly on the phenolic acid content. Our results suggest that short steam heating in peeling process improves the stability of the chlorogenic acid in PPW, whereas raw peeling results in fast degradation of the compound. In addition to SCP production, processing and storage conditions of PPW are also crucial if phenolic compounds are to be recovered from other side streams of potato industry.

\section{Conclusions}

The present work indicates that the PPW, with minor supplementation, is a suitable raw material for the production of SCP. The acidic hydrolysate of the PPW can be used for the cultivation of acidophilic fungus under non-aseptic conditions without major risk of contamination which is an advance compared to traditional bioprocesses. The achieved reduction of organic load was not at a sufficient level for wastewater treatment, and therefore process optimization would be necessary.

\section{Acknowledgements}

This research was financed by the European Regional Development Fund project A70161. 


\section{References}

[1] Helsky, T., Anttalainen, M., Palviainen, S., Kemppainen, P., Lehto, M., Salo, T., et al. (2006) Best Available Technique (BAT) for the Automated Peeling and Processing of Potato and Other Root Vegetables. Edita Prima Oy, Helsinki.

[2] Bodner, J.M. and Sieg, J. (2009) Fiber. In: Ingredients in Meat Products, Springer, New York, 83-109. https://doi.org/10.1007/978-0-387-71327-4_4

[3] Camire, M.E., Violette, D., Dougherty, M.P. and McLaughlin, M.A. (1997) Potato Peel Dietary Fiber Composition: Effects of Peeling and Extrusion Cooking Processes. Journal of Agricultural and Food Chemistry, 45, 1404-1408. https://doi.org/10.1021/jf9604293

[4] Perez, S., Baldwin, P.M. and Gallant, D.J. (2009) Structural Features of Starch Granules I. Starch: Chemistry and Technology, 3, 11-21.

[5] Rommi, K., Rahikainen, J., Vartiainen, J., Holopainen, U., Lahtinen, P., Honkapää, K., et al. (2016) Potato Peeling Costreams as Raw Materials for Biopolymer Film Preparation. Journal of Applied Polymer Science, 133, No. 5. https://doi.org/10.1002/app.42862

[6] Meyer, A.S., Dam, B.P. and Laerke, H.N. (2009) Enzymatic Solubilization of a Pectinaceous Dietary Fiber Fraction from Potato Pulp: Optimization of the Fiber Extraction Process. Biochemical Engineering Journal, 43, 106-112. https://doi.org/10.1016/j.bej.2008.09.006

[7] Arapoglou, D., Varzakas, T., Vlyssides, A. and Israilides, C. (2010) Ethanol Production from Potato Peel Waste (PPW). Waste Management, 30, 1898-1902. https://doi.org/10.1016/j.wasman.2010.04.017

[8] Liang, S., McDonald, A.G. and Coats, E.R. (2014) Lactic Acid Production with Undefined Mixed Culture Fermentation of Potato Peel Waste. Waste Management, 34, 2022-2027. https://doi.org/10.1016/j.wasman.2014.07.009

[9] Bacha, U., Nasir, M., Khalique, A., Anjum, A.A. and Jabbar, M.A. (2011) Comparative Assessment of Various Agro-Industrial Wastes for Saccharomyces cerevisiae Biomass Production and Its Quality Evaluation as Single Cell Protein. Journal of Animal and Plant Sciences, 21, 844-849.

[10] Tomlinson, E.J. (1976) The Production of Single-Cell Protein from Strong Organic Waste Waters from the Food and Drink Processing Industries. Laboratory Cultures. Water Research, 10, 367-371. https://doi.org/10.1016/0043-1354(76)90053-1

[11] Tomlinson, E.J. (1976) The Production of Single-Cell Protein from Strong Organic Waste Waters from the Food and Drink Processing Industries. The Practical and Economic Feasibility of a Non-Aseptic Batch Culture. Water Research, 10, 372-376. https://doi.org/10.1016/0043-1354(76)90054-3

[12] Stevens, C.A. and Gregory, K.F. (1987) Production of Microbial Biomass Protein from Potato Processing Wastes by Cephalosporium eichhorniae. Applied and Environmental Microbiology, 53, 284-291.

[13] Ivarson, K.C. and Morita, H. (1982) Single-Cell Protein-Production by the Acid-Tolerant Fungus Scytalidium acidophilum from Acid Hydrolysates of Waste Paper. Applied and Environmental Microbiology, 43, 643-647.

[14] Sigler, L. and Carmichael, J.W. (1974) A New Acidophilic Scytalidium. Canadian Journal of Microbiology, 20, 267-268. https://doi.org/10.1139/m74-043

[15] Starkey, R.L. and Waksman, S.A. (1943) Fungi Tolerant to Extreme Acidity and High Concentrations of Copper Sulfate. Journal of Bacteriology, 45, 509-519.

[16] Martin, A.M. and White, M.D. (1985) Growth of the Acid-Tolerant Fungus Scytali- 
dium acidophilum as a Potential Source of Single-Cell Protein. Journal of Food Science, 50, 197-200. https://doi.org/10.1111/j.1365-2621.1985.tb13308.x

[17] Martin, A.M., Chintalapati, S.P. and Hoover, R. (1990) Assessment of Acid Hydrolysates of Peat as Substrate for Scytalidium acidophilum ATCC-26774 Fungus. Journal of Chemical Technology and Biotechnology, 49, 3-13. https://doi.org/10.1002/jctb.280490103

[18] Martin, A.M. (1999) A Low-Energy Process for the Conversion of Fisheries Waste Biomass. Renewable Energy, 16, 1102-1105. https://doi.org/10.1016/S0960-1481(98)00428-5

[19] Martin, A.M. and Chintalapati, S.P. (1989) Fish Offal-Peat Compost Extracts as Fermentation Substrate. Biological Wastes, 27, 281-288. https://doi.org/10.1016/0269-7483(89)90009-8

[20] Anupama and Ravindra, P. (2000) Value-Added Food: Single Cell Protein. Biotechnology Advances, 18, 459-479. https://doi.org/10.1016/S0734-9750(00)00045-8

[21] Akyol, H., Riciputi, Y., Capanoglu, E., Caboni, M.F. and Verardo, V. (2016) Phenolic Compounds in the Potato and Its Byproducts: An Overview. International Journal of Molecular Sciences, 17, 835. https://doi.org/10.3390/ijms17060835

[22] Albin, D.M., Wubben, J.E. and Gabert, V.M. (2000) Effect of Hydrolysis Time on the Determination of Amino Acids in Samples of Soybean Products with Ion-Exchange Chromatography or Precolumn Derivatization with Phenyl Isothiocyanate. Journal of Agricultural and Food Chemistry, 48, 1684-1691. https://doi.org/10.1021/jf990599q

[23] Spilioti, E., Jaakkola, M., Tolonen, T., Lipponen, M., Virtanen, V., Chinou, I., et al. (2014) Phenolic Acid Composition, Antiatherogenic and Anticancer Potential of Honeys Derived from Various Regions in Greece. PLoS ONE, 9, e94860. https://doi.org/10.1371/journal.pone.0094860

[24] Tsiapara, A.V., Jaakkola, M., Chinou, I., Graikou, K., Tolonen, T., Virtanen, V., et al. (2009) Bioactivity of Greek Honey Extracts on Breast Cancer (MCF-7), Prostate Cancer (PC-3) and Endometrial Cancer (Ishikawa) Cells: Profile Analysis of Extracts. Food Chemistry, 116, 702-708.

https://doi.org/10.1016/j.foodchem.2009.03.024

[25] Eriksson, L., Johansson, E., Kettaneh-Wold, N., Wikström, C. and Wold, S. (2008) Design of Experiments: Principles and Applications. 3rd Edition, Umetrics Academy, Stockholm.

[26] Koza, C.R., Norton, G.A. and van Leeuwen, J. (2017) Dewatering Investigations on Fungal Biomass Grown in Thin Stillage from a Dry-Mill Corn Ethanol Plant. Biomass and Bioenergy, 97, 65-69. https://doi.org/10.1016/j.biombioe.2016.12.011

[27] Mishra, B.K., Arora, A. and Lata, N. (2004) Optimization of a Biological Process for Treating Potato Chips Industry Wastewater Using a Mixed Culture of Aspergillus foetidus and Aspergillus niger. Bioresource Technology, 94, 9-12.

https://doi.org/10.1016/j.biortech.2003.11.020

[28] Huang, L.P., Jin, B., Lant, P. and Zhou, J. (2003) Biotechnological Production of Lactic Acid Integrated with Potato Wastewater Treatment by Rhizopus arrhizus. Journal of Chemical Technology and Biotechnology, 78, 899-906. https://doi.org/10.1002/jctb.877

[29] Dao, L. and Friedman, M. (1992) Chlorogenic Acid Content of Fresh and Processed Potatoes Determined by Ultraviolet Spectrophotometry. Journal of Agricultural and Food Chemistry, 40, 2152-2156. https://doi.org/10.1021/jf00023a022 